\title{
Marketing of goat at different age and weight by different categories of farmers in selected areas of Bangladesh
}

\author{
MA Khatun, MR Alam ${ }^{1}$, MR Amin* and MSI Khan
}

Department of Animal Science, Bangladesh Agricultural University, Mymensingh 2202, Bangladesh

${ }^{1}$ School of Sustainable Agriculture, University of Malaysia, Sabah, Malaysia

\begin{abstract}
The factors influencing marketing of goats at different age and weight by different categories of farmers were investigated. The data were collected from village market (Hat) in selected places of Sirajgonj, Rajshahi, Kushtia, Mymensingh and Tangail districts. Goat owners belonged to one of the 4 categories of farmers at the Hat were interviewed through pre-tested questionnaire and the weight, body size and age of goats were determined. Landless and marginal farmers sold $58.81 \%$ of their goats at 6 months, $42.94 \%$ of small farmers at 10.5 months and $50 \%$ of medium farmers at 15.5 months of age. The average market weight and age of goats belonged to above categories of farmers were 8.39, 12.89, 17.10 and $17.20 \mathrm{~kg}$ and $6,10.5,15.5$ and more than 18 months of age, respectively. The potential market weight of goats was found $17.10 \mathrm{~kg}$ at the age of 15.5 months. About $84 \%$ of farmers of all categories sold their goats for cash income, $15 \%$ for rearing problems and only $1 \%$ for disease prevalence.
\end{abstract}

Key words: Goats, market, age, weight and farmers category

Bangladesh Animal Husbandry Association. All rights reserved.

Bang. J. Anim. Sci. 2012. 41 (1): 55-59

\section{Introduction}

Goats are reared in small holding system as a popular ruminant species for household income due to its higher market value for meat. The reasons include taste preference, prestige, religion, tradition and availability with the nutritional aspects being included more recently. Bangladesh has the third highest population of goats among the Asiatic countries which accounts for about 34.5 million heads representing $57 \%$ of total ruminant livestock (FAO, 2003) of which $98 \%$ is distributed in the rural areas (BBS, 1986). According to DLS (2004), annual slaughter rate of goat and cattle was $38 \%$ and $16 \%$, respectively. The meat production from goat was 0.73 million MT against total meat production of 1.26 million MT (DLS, 2010). Although the demand for meat has increased, the actual supply of meat from ruminant livestock has declined. In order to increase the supply of meat in the market either more heads of animals need to be slaughtered or by increasing the yield per animal. Increase of yield per animal is more justifiable in resource constraint situation of Bangladesh.

Among the ruminants $96 \%$ of goats are thrives in traditional scavenging system with minimum care. Black Bengal goat is predominant breed for its special attributes to its prolificacy, higher value of meat and produce $26 \%$ of total livestock products. Subsistence level of goat farming is a combination of scavenging, free grazing in the fallow land and depending on availability tree leaves and crop by-products are offered as supplement (Alam 1993; Hossain 2006). This is more prevalent among the small holder farmers for supplementation to their income compared to large farmers who rear as an investment. This study was undertaken to investigate the factors influencing marketing of goats by different categories of farmers and potential of contribution of goat to the farmers and its products to the market in existing farming systems.

\section{Materials and Methods}

Market survey was conducted to determine the factors affecting selling of goats at different weight and age by different categories of farmers. Six village markets (Hat), namely Talgachi and Gas line Hat in Sirajgonj, Banesshor Hat in Rajshahi, Sheikpara Hat in Kushtia, Shomvugonj Hat in Mymensingh and Ghatail Hat in Tangail were selected for collection of information by pretested interview schedule during July to December, 2009. Data were collected from each place at 20 to 30 days interval for obtaining at least 10 numbers of farmers for each category. Care was taken to 
explain to the respondent if failed to understand any question.

Farmers were categorized into landless, marginal, small, medium and large farmers on the basis of owing cultivable land as $<0.5,0.55-1.48,1.49$ $2.5,2.51-4.0$, and $>4.0$, respectively, adopted by Directorate of Agriculture Extension in Bangladesh.

Opinion for the reason for selling goats was recorded directly from the respondents. Market weight of goats was taken on site by using radial weighing balance. Age of the goats was estimated through dentition and examined teeth according to Miller and Robertson (1959) and estimated age was cross examined with the owners. Market size of goat (height $x$ length of goat) was measured by using a measuring tape. Height of goat was taken from top of shoulder to base of foot and length of goat was taken from point of shoulder to point of hip (in inch).

Data were tabulated, structured, edited and analyzed for analyses of variances using Statistical Package for Social Science (SPSS) version 11.5 computer program.

\section{Results and Discussion}

\section{Category of farmers involved in rearing and marketing of goats}

The different categories of farmer at different locations on the basis of marketing of goats are represented in Table 1 . Irrespective of the locations, landless and marginal farmers were brought significantly higher number of goats to the market for sale than that of small and medium farmers $(p<0.01)$. On an average, higher number of goats was marketed by marginal farmers followed by landless, small and medium farmers. Highest numbers of the landless farmers were found engaged in rearing and marketing of goats in Mymensingh and lowest in Kushtia districts, respectively $(p<0.01)$. The same trend was observed in Rajshahi where landless farmers were found higher $(p<0.01)$ followed by marginal, small and medium farmers. There was no significant difference $(p>0.01)$ among the landless farmers and marginal farmers in marketing of goats in Sirajgonj. Among all the farmers, more marginal farmers were involved in rearing and marketing than landless, small and medium farmers in Kushtia. On the contrary, landless farmers in Mymensingh were higher in terms of selling goats followed by marginal, small and medium farmers $(p<0.01)$. Among the farmers in Tangail, the percent of landless and marginal farmers were not different but small and medium farmers were differed significantly $(p<0.01)$ in trading goats. From the above observation, it is evident that the majority of goats were brought to market by landless and marginal farmers followed by small and medium farmers. On an average only $7 \%$ of medium farmers were engaged in goat farming and large farmers were less interested for goat rearing and selling. Large farmers found to have interest in cattle than goat rearing. Therefore, majority of the farmers in the study areas are landless, marginal or small farmers who reared and sold more goats to local Hat and were the large contributors of goat in the market.

Table 1. Different categories (\%) of farmers at different locations involved in marketing of goats

\begin{tabular}{lcccc}
\hline \multirow{2}{*}{ Locations } & \multicolumn{4}{c}{ Farmer categories } \\
\cline { 2 - 5 } & Landless & Marginal & Small & Medium \\
\hline Sirajgonj & $36^{\mathrm{a}}$ & $35^{\mathrm{a}}$ & $24^{\mathrm{b}}$ & $4^{\mathrm{c}}$ \\
Rajshahi & $39^{\mathrm{a}}$ & $30^{\mathrm{b}}$ & $25^{\mathrm{c}}$ & $7^{\mathrm{d}}$ \\
Kushtia & $10^{\mathrm{d}}$ & $40^{\mathrm{a}}$ & $30^{\mathrm{b}}$ & $17^{\mathrm{c}}$ \\
Mymensingh & $44^{\mathrm{a}}$ & $29^{\mathrm{b}}$ & $21^{\mathrm{c}}$ & $6^{\mathrm{d}}$ \\
Tangail & $34^{\mathrm{a}}$ & $34^{\mathrm{a}}$ & $29^{\mathrm{b}}$ & $3^{\mathrm{c}}$ \\
Mean & $33^{\mathrm{a}}$ & $34^{\mathrm{a}}$ & $26^{\mathrm{b}}$ & $7^{\mathrm{c}}$ \\
\pm SE & \pm 5.90 & \pm 1.96 & \pm 1.66 & \pm 2.50 \\
\hline
\end{tabular}

Means with different superscripts in the same row differ significantly $(p<0.01)$; SE, standard error

\section{Market age of goats}

The percent of different ages goats sold at different locations is shown in Table 2. From overall marketing age of goats it was observed that there was a trend of selling higher number of goats $(p<0.05)$ at the age of 6 months by all categories of farmers followed by 10.5, 15.5 and 18 or above 18 months of age. Farmers belonged to Rajshahi, Mymensingh and Tangail areas brought higher numbers of their goats and marketed at 6 months of age compared to farmers in Kushtia and Sirajgonj. Farmers in Kushtia were found to market goats when they reached towards more mature age $(p<0.01)$. In an earlier study, Alam (2000) reported market age of goats was 9 months. Indiscriminate marketing of goats at different ages were probably due to the need for cash income by the resource-poor farmers. 
Table 2. Percent of different age of goats sold at different location

\begin{tabular}{lcccc}
\hline Location & \multicolumn{4}{c}{ Average age group } \\
\cline { 2 - 5 } & $6 \mathrm{mo}$. & $10.5 \mathrm{mo}$. & $15.5 \mathrm{mo}$. & $\begin{array}{l}>18 \\
\mathrm{mo} .\end{array}$ \\
\hline Sirajgonj & $38.76^{\mathrm{a}}$ & $32.97^{\mathrm{b}}$ & $26.37^{\mathrm{c}}$ & $2.2^{\mathrm{d}}$ \\
\hline Rajshahi & $57.86^{\mathrm{a}}$ & $22.7^{\mathrm{b}}$ & $18.2^{\mathrm{c}}$ & $1.1^{\mathrm{d}}$ \\
\hline Kushtia & $26.7^{\mathrm{b}}$ & $40.0^{\mathrm{a}}$ & $13.3^{\mathrm{c}}$ & $20.0^{\mathrm{d}}$ \\
\hline Mymensingh & $55.88^{\mathrm{a}}$ & $14.71^{\mathrm{b}}$ & $14.71^{\mathrm{b}}$ & $14.71^{\mathrm{b}}$ \\
\hline Tangail & $51.43^{\mathrm{a}}$ & $22.86^{\mathrm{b}}$ & $14.29^{\mathrm{c}}$ & $11.43^{\mathrm{d}}$ \\
\hline Mean & $46.13^{\mathrm{a}}$ & $26.65^{\mathrm{b}}$ & $17.37^{\mathrm{c}}$ & $9.89^{\mathrm{d}}$ \\
\pm SE & \pm 5.92 & \pm 4.42 & \pm 2.40 & \pm 3.63 \\
\hline Means with & different & & & \\
\hline
\end{tabular}

Means with different superscripts in the same row differ significantly $(p<0.05)$; SE, standard error

\section{Age of goats sold by different categories of farmers}

The percent of different age of goats sold by different categories of farmers is shown in Table 3. It was observed that resource-poor farmers of landless and marginal categories marketed higher number of goats at the age of 6 months than that of small and medium farmers. Small farmers sold more goats at the age of 10.5 months followed by landless, marginal and medium categories of farmers, respectively. There was a trend of selling more goats at the age of 15.5 months by medium farmers compared to other farmers $(p<0.01)$ and their trend of selling goats at the age of 6 months was less $(p<0.01)$. Rearing of goats is considered as income generating activities in farms and among them $62.87 \%$ and $54.74 \%$ of landless and marginal farmers, respectively sold their goats at the time of immediate family need for cash before being reached to higher market weight. Alam (2007) postulated that farmers would earn $53 \%$ more income and meet $27 \%$ of family need for cash through effective policies and concerted efforts on rearing and marketing of goats.

Table 3. Percent of different age of goats sold by different categories of farmers

\begin{tabular}{lcccc}
\hline \multirow{2}{*}{$\begin{array}{l}\text { carm } \\
\text { category }\end{array}$} & $6 \mathrm{mo}$. & $10.5 \mathrm{mo}$. & $15.5 \mathrm{mo}$. & $>18 \mathrm{mo}$. \\
\cline { 2 - 5 } Landless & $62.87^{\mathrm{a}}$ & $24.36^{\mathrm{b}}$ & $8.92^{\mathrm{c}}$ & $3.85^{\mathrm{d}}$ \\
\hline Marginal & $54.74^{\mathrm{a}}$ & $26.10^{\mathrm{b}}$ & $12.26^{\mathrm{c}}$ & $6.9^{\mathrm{d}}$ \\
\hline Small & $29.56^{\mathrm{b}}$ & $42.94^{\mathrm{a}}$ & $21.25^{\mathrm{c}}$ & $6.25^{\mathrm{d}}$ \\
\hline Medium & $5.55^{\mathrm{d}}$ & $33.33^{\mathrm{b}}$ & $50^{\mathrm{a}}$ & $11.11^{\mathrm{c}}$ \\
\hline Mean & $38.18^{\mathrm{a}}$ & $31.68^{\mathrm{b}}$ & $23.11^{\mathrm{ab}}$ & $7.03^{\mathrm{c}}$ \\
\pm SE & \pm 12.98 & \pm 4.23 & \pm 9.33 & \pm 1.51 \\
\hline
\end{tabular}

Means with different superscripts in the same row differ significantly $(p<0.01)$; SE, standard error

\section{Market weight of goats at different locations}

The average live weight of different market age of goats at different locations is shown in Table 4. Irrespective of the locations, there was a difference $(p<0.05)$ in live weight among the goats brought for selling at their average marketing age of 6 months, 10.5 months, 15.5 months and more than 18 months, respectively. The farmers in Kushtia were found to market their goats when they reached to heavier live weight than other places of study $(p<0.05)$. It is evident that majority of landless and marginal farmers in these locations who are involved in rearing and marketing of goats sold higher percentage of goats (Table 2) at the age of 6 months at significantly less weight $(p<0.05)$. Marketing of goats at less live weight and age was not based on market demand of matured age and weight. According to Alam (2007) consumers in the country preferred goat carcass at $15 \mathrm{~kg}$ live weight. This finding also suggests that need for cash income was important determinant for marketing of goats and was not based on demand of quality meat.

Table 4. Live weight of different market ages of goats at different locations

\begin{tabular}{lcccc}
\hline Location & \multicolumn{4}{c}{ Average weight of goats $(\mathrm{kg})$} \\
\cline { 2 - 5 } & $6 \mathrm{mo}$. & $10.5 \mathrm{mo}$. & $15.5 \mathrm{mo}$. & $>18 \mathrm{mo}$ \\
\hline Sirajgonj & $7.87^{\mathrm{d}}$ & $12.25^{\mathrm{c}}$ & $15.50^{\mathrm{b}}$ & $17.33^{\mathrm{a}}$ \\
\hline Rajshahi & $5.88^{\mathrm{d}}$ & $11.58^{\mathrm{c}}$ & $14.05^{\mathrm{b}}$ & $16.89^{\mathrm{a}}$ \\
\hline Kushtia & $10.0^{\mathrm{d}}$ & $14.61^{\mathrm{c}}$ & $24.34^{\mathrm{a}}$ & $19.90^{\mathrm{b}}$ \\
\hline Mymensingh & $8.72^{\mathrm{d}}$ & $12.70^{\mathrm{c}}$ & $15.30^{\mathrm{b}}$ & $15.87^{\mathrm{a}}$ \\
\hline Tangail & $8.6^{\mathrm{d}}$ & $11.96^{\mathrm{c}}$ & $14.89^{\mathrm{b}}$ & $16.10^{\mathrm{a}}$ \\
\hline Mean & $8.21^{\mathrm{d}}$ & $12.62^{\mathrm{c}}$ & $16.81^{\mathrm{b}}$ & $17.22^{\mathrm{a}}$ \\
\pm SE & \pm 0.68 & \pm 0.53 & \pm 1.90 & \pm 0.72 \\
\hline
\end{tabular}

Means with different superscripts in the same row differ significantly $(p<0.05)$; SE, standard error

\section{Average live weight of goats at different market age}

The average live weight of different market age of goats belonged to different categories of farmers is given in Table 5. Similar to the different locations, there was a trend for marketing of goats on the average live weights of $8.39,12.89,17.10$ and $17.20 \mathrm{~kg}$ at the age of 6 months, 10.5 months, 15.5 months and above 18 months, respectively. There was a clear evidence of the difference in live weight $(p<0.05)$ with the advance of age from 6 to 15.5 months. These differences were not significant when the goats 
Khatun et al. (2012) Bang. J. Anim. Sci. 41 (1): 55-59

were found marketed at the age of 18 months

and above.

Table 5. Live weight of goats at different ages belonged to different farm categories

\begin{tabular}{lcccc}
\hline Farm category & \multicolumn{4}{c}{ Average live weight of goats $(\mathrm{kg}) \pm \mathrm{SE}$} \\
\cline { 2 - 5 } & 6 months & 10.5 months & 15.5 months & $>18$ months \\
\hline Landless & $6.14^{\mathrm{d}} \pm 0.30$ & $11.37^{\mathrm{c}} \pm 0.70$ & $14.90^{\mathrm{b}} \pm 0.87$ & $15.20^{\mathrm{a}} \pm 1.10$ \\
Marginal & $8.78^{\mathrm{d}} \pm 1.40$ & $11.80^{\mathrm{c}} \pm 0.82$ & $16.50^{\mathrm{b}} \pm 0.76$ & $16.80^{\mathrm{a}} \pm 0.97$ \\
Small & $8.90^{\mathrm{c}} \pm 0.73$ & $12.90^{\mathrm{b}} \pm 0.98$ & $17.30^{\mathrm{a}} \pm 0.95$ & $17.30^{\mathrm{a}} \pm 0.88$ \\
Medium & $9.80^{\mathrm{d}} \pm 0.0$ & $15.33^{\mathrm{c}} \pm 1.39$ & $19.70^{\mathrm{a}} \pm 0.47$ & $19.50^{\mathrm{b}} \pm 0.69$ \\
\hline Mean & $8.39^{\mathrm{d}} \pm 0.79$ & $12.89^{\mathrm{c}} \pm 0.89$ & $17.10^{\mathrm{b}} \pm 1.00$ & $17.20^{\mathrm{a}} \pm 0.89$ \\
\hline
\end{tabular}

Means with different superscripts in the same row differ significantly $(p<0.05)$; SE, standard error

It appears that goats are sold at live weight ranged from 8.39 to $17.20 \mathrm{~kg}$. The potential improvement of market weight of goats was found $17.10 \mathrm{~kg}$ at 15.5 months of age. Thereafter, very less numbers of goats were found in the market beyond this live weight. Therefore, this live weight is appeared to be the potential market weights of goats in the existing marketing systems of goats.

Table 6. The reasons for selling of goats by different categories of farmers at different locations

\begin{tabular}{|c|c|c|c|c|}
\hline \multirow{2}{*}{ Location } & \multirow{2}{*}{$\begin{array}{l}\text { Farmer } \\
\text { category }\end{array}$} & \multicolumn{3}{|c|}{$\begin{array}{l}\text { Reasons for selling } \\
\text { ( } \% \text { respondents) }\end{array}$} \\
\hline & & Cash & $\begin{array}{l}\text { Rearing } \\
\text { problems }\end{array}$ & Diseases \\
\hline \multirow{4}{*}{ Sirajgonj } & Landless & 82 & 18 & - \\
\hline & Marginal & 79 & 21 & - \\
\hline & Small & 94 & 6 & - \\
\hline & Medium & 95 & 5 & - \\
\hline \multirow{4}{*}{ Rajshahi } & Landless & 80 & 15 & 5 \\
\hline & Marginal & 88 & 12 & - \\
\hline & Small & 90 & 10 & - \\
\hline & Medium & 92 & 8 & - \\
\hline \multirow{4}{*}{ Kushtia } & Landless & 100 & - & - \\
\hline & Marginal & 75 & 17 & 8 \\
\hline & Small & 87 & 13 & - \\
\hline & Medium & 92 & 8 & - \\
\hline \multirow{4}{*}{ Mymensingh } & Landless & 60 & 40 & - \\
\hline & Marginal & 80 & 20 & - \\
\hline & Small & 86 & 14 & - \\
\hline & Medium & 91 & 9 & - \\
\hline \multirow{4}{*}{ Ghatail } & Landless & 68 & 32 & - \\
\hline & Marginal & 77 & 23 & - \\
\hline & Small & 81 & 19 & - \\
\hline & Medium & 90 & 10 & - \\
\hline Mean & & 84.35 & 15 & 0.65 \\
\hline
\end{tabular}

\section{Reasons for selling of goats by different categories of farmers}

The reasons for selling of goats by different categories of farmers at different locations are shown in Table 6. It was observed that about $84 \%$ of farmers of all categories sold their goats for cash income to meet immediate family needs such as wedding, festivals and medical treatment and only $15 \%$ farmers for rearing problem. During the cropping seasons when goats could not graze freely and lack of man power for the preoccupation with cultivation were main rearing problems. Surprisingly, less than $1 \%$ of all categories of the farmers in their opinion diseases were fewer problems for goats and contrary to the findings of diseases as the main problem of rearing observed by Alam et al. (2000) Therefore, goats are considered for cash income to meet the needs of the family and sold whenever owners were in need of money to meet the expenses.

It is apparent from this study that despite of rearing difficulties, farmers consider goats as generating family income and not influenced by the problems of rearing and diseases. It is also revealed that majority of goats would have been brought to market at higher live weight and sold at higher price if their immediate need for cash was met. Farmers were also felt for fair price of goats on the basis of weight, age and body condition. The prevailing visual assessment and negotiation of price of goat in most of the cases underestimate the value. Consequently, farmers felt discouraged in rearing and selling goats at higher market weight. As prevailed in some of the agricultural commodities in the country incentive to meet immediate family needs together with adoption of good rearing practices may encourage majority of goat owners to rear and sell at higher live weight which in turn increase meat and skin production by two fold in the country. 


\section{Marketing of goat in Bangladesh}

\section{Conclusion}

It is concluded that the present indiscriminate marketing of goats is influenced by the need of cash income by resource-poor farmers and their inability to manage goats due to involvement in cropping. In the prevailing free grazing system majority of the landless farmers in Mymensingh and Rajshahi districts and marginal farmers in Sirajganj and Kushtia districts marketed goats to support family needs. Adoption of effective policies in terms of incentives on goat rearing, market weight, body condition and age of goats would generate additional income, increase in meat and skin production under existing goat farming systems in the country.

\section{References}

Alam MR (1993). Studies on feeding systems for the development of production strategies for goats in Bangladesh. In : Feeding strategies for improving ruminant productivity in areas of fluctuating nutrient supply. International Atomic Energy Agency, Vienna, IAEA TECDOC 691, P. 135-143.

Alam MR (2000). Goat raising in small-holder farming systems in Bangladesh. In: Proccedings of 7th International Conference on Goats, 15-18 May, 2000, Tours, France, 1: 329-330.

Alam MR, Sarkar RI, Hossain MD and Islam MS (2000). Contribution of livestock to small farmers in Bangladesh, Asian-Australian Journal of Animal Science, 13: 339-342.

Alam MR (2007). Influence of farming systems on goat production, carcass quality and economic contribution to farmers in Bangladesh. In: The Quality of Goat Products. Proc. 25th International Goat Symposium, 24-26 May, 2007, BellaMoliterno, Italy. P. 105-108.

BBS (1986). Statistical Yearbook of Bangladesh, Bangladesh Bureau of Statistics. Ministry of planning, Planning Division, Government of the People Republic of Bangladesh.

DLS (2004). Development and work plan, Department of Livestock Services. Ministry of Livestock and Fishery, Dhaka, Bangladesh.

DLS (2010). Development and work plan, Department of Livestock Services, Ministry of Livestock and Fishery, Dhaka, Bangladesh.

FAO (2003). Production Year Book, Food and Agricultural Organization, Rome, Italy.

Hossain MM (2006). A report on importance of indigenous tree pods/fruits in goats diets in Bangladesh. DFID-LPP project ZC 0305, Department of Animal Science, Bang. Agril. Univ..

Miller WC and Robertson EDS (1959). Practical Animal Husbandry (Seventh edition). Oliver and Boyd. Edinburgh, U. K. 